\title{
FOXC1 induces cancer stem cell-like properties through upregulation of beta- catenin in NSCLC
}

Sisi Cao ${ }^{1 \dagger}$, Zhuo Wang ${ }^{1 \dagger}$, Xiujuan Gao ${ }^{1}$, Wenjuan $\mathrm{He}^{1}$, Yue Cai ${ }^{1}$, Hui Chen ${ }^{1,2^{*}}$ and Rong $\mathrm{Xu}^{1,2^{*}}$

\begin{abstract}
Background: Accumulating evidence suggests that cancer stem cells (CSCS) play a critical role in tumor initiation, progression and therapy, and recent studies have indicated that Forkhead box C1 (FOXC1) is strongly associated with CSCs. This study investigates the regulatory effects of FOXC1 on CSC-like properties in non-small cell lung cancer (NSCLC).
\end{abstract}

Methods: We analyzed FOXC1 expression in NSCLC using the Cancer Genome Atlas (TCGA) database on UALCANC and performed survival analyses of NSCLC patients on Human Protein Atlas. CSC-like properties were analyzed based on CSC marker-positive cell population, self-renewal ability, stemness-related gene expression, tumorigenicity and drug resistance. The percentage of $\mathrm{CD}_{133^{+}}$cells was analyzed by flow cytometric analysis. Self-renewal ability was detected by sphere-formation analysis. Real-time PCR, western blotting and immunohistochemical staining were employed to detect mRNA and protein levels. Tumorigenicity was determined based on a xenograft formation assay, and effects of FOXC1 on drug resistance were assessed by cell viability and apoptosis assays. Luciferase reporter and chromatin immunoprecipitation (ChIP) assays were used to investigate the binding of FOXC1 to beta-catenin promoter.

Results: FOXC1 expression was found to be elevated in NSCLC tissues and negatively correlated with patient survival. FOXC1 knockdown reduced $\mathrm{CD} 133^{+}$cell percentage, suppressed self-renewal ability, decreased expression of stemness-related genes (Oct4, NANOG, SOX2 and ABCG2) and inhibited NSCLC cell tumorigenicity in vivo. Moreover, FOXC1 knockdown increased cisplatin and docetaxel sensitivity and reduced gefitinib resistance, whereas FOXC1 overexpression enhanced CSC-like properties. Luciferase reporter and ChIP assays showed beta-catenin to be a direct transcriptional target of FOXC1. Furthermore, overexpression of beta-catenin reversed the CSC-like property inhibition induced by FOXC1 knockdown, and knockdown of beta-catenin attenuated the CSC-like properties induced by FOXC1 overexpression.

Conclusions: This study demonstrates that FOXC1 induces CSC-like properties in NSCLC by promoting beta-catenin expression. The findings indicate that FOXC1 is a potential molecular target for anti-CSC-based therapies in NSCLC.

Keywords: FOXC1, Cancer stem cell-like properties, Beta-catenin, NSCLC

\footnotetext{
*Correspondence: chenhuitj@mails.tjmu.edu.cn; rongxu@hust.edu.cn

†Sisi Cao and Zhuo Wang contributed equally to this work.

'Department of Pharmacology, School of Basic Medicine, Tongji Medical

College, Huazhong University of Science and Technology, Wuhan 430030,

Hubei, China

Full list of author information is available at the end of the article
}

(c) The Author(s). 2018 Open Access This article is distributed under the terms of the Creative Commons Attribution 4.0 International License (http://creativecommons.org/licenses/by/4.0/), which permits unrestricted use, distribution, and reproduction in any medium, provided you give appropriate credit to the original author(s) and the source, provide a link to the Creative Commons license, and indicate if changes were made. The Creative Commons Public Domain Dedication waiver (http://creativecommons.org/publicdomain/zero/1.0/) applies to the data made available in this article, unless otherwise stated. 


\section{Background}

Lung cancer is the most common cancer and is the leading cause of cancer death [1]. Despite rapid advances in cancer treatment, the prognosis of lung cancer patients remains less than optimal. The 5-year survival rate in lung cancer patients is 4-17\%, depending on tumor stage and region [2, 3]. Cancer stem cells (CSCs), a small population of cancer cells that retain stem cell properties $[4,5]$, play an essential role in tumor initiation, progression and therapy. The self-renewal and differentiation of CSCs are responsible for tumor initiation and maintenance. CSCs also act as tumorigenic cells in metastasis. Moreover, CSCs exhibit resistance to anticancer drugs, and CSCs remaining after therapy lead to cancer recurrence. Because of the conspicuous role of CSCs in tumor initiation, maintenance, metastasis, drug resistance and recurrence, inhibiting CSCs by targeting signaling pathways that regulate these cells is an effective anti-lung cancer strategy [6].

Forkhead box (FOX) proteins, characterized by a winged helix DNA-binding domain [7], are important transcription factors $[8,9]$, and many FOX family members play a critical role in cancer progression [10-13]. Previous studies have proven that FOX proteins are strongly associated with CSCs. For example, downregulation of FOXA1 expression promotes CSC-like properties in breast cancer cells, leading to tamoxifen resistance [14]. FOXM1 increases the CSC population and induces endocrine resistance in breast cancer [15], and FOXQ1 inhibition with diallyl disulfide is a novel strategy for suppressing breast CSCs [16]. Forkhead box C1 (FOXC1), a member of the FOX protein family, acts as an oncogene in various cancers [17]. For instance, FOXC1 mRNA and protein levels are upregulated in $60 \%$ and $63.3 \%$, respectively, of patients with non-small cell lung cancer (NSCLC), which is the main type of lung cancer, and FOXC1 knockdown inhibits proliferation and metastasis in NSCLC [18-20]. FOXC1 also promotes proliferation, migration, invasion and drug resistance in hepatocellular carcinoma [21,22] and breast cancer [23-26]. Recently, several studies have shown that FOXC1 governs hair follicle stem cell quiescence to maintain regenerating potential [27, 28]. Hedgehog and Notch are essential pathways in CSC regulation [29]. FOXC1 activates Notch pathway by directly regulating Dll4 in endothelial cells [30] and enhances Hedgehog signaling activity via Gli2 binding in basal-like breast cancer [31]. Moreover, FOXC2 has been shown to enhance CSC-like properties in breast cancer and prostate cancer [32, 33]. These findings emphasize the role of FOX proteins in regulating CSCs.

Nonetheless, there is no report on the function of FOXC1 in the regulation of CSCs in NSCLC. This study is the first to investigate $\mathrm{FOXC1}$ induction of CSC-like properties in NSCLC, and we hope that the findings will provide a foundation for NSCLC therapy via CSC eradication.

\section{Methods}

\section{Cells and cell culture}

HBE, A549, NCI-H292, NCI-H1299, NCI-H1975 and HCC827 cells were purchased from the Cell Bank of Type Culture Collection of the Chinese Academy of Sciences (China). PC9 cells were purchased from the RIKEN BioResource Center (Japan). The gefitinib-resistant PC9/G cell line was produced in our laboratory following a previously described procedure [34]. All cell lines were cultured as described in the providers' instructions and were authenticated via short tandem repeat (STR) genotyping analysis.

\section{Real-time PCR}

Total RNA was extracted from NSCLC cells using RNApure (ZOMANBIO, China) and reverse-transcribed into cDNA using a Reverse Transcriptase Kit (ZOMANBIO). HSYBR qPCR Mix (ZOMANBIO) was used to perform real-time PCR with primers for FOXC1 (HQP005629), beta-catenin (HQP003539), NANOG (HQP019390), Oct4 (HQP464025), SOX2 (HQP017628), ABCG2 (HQP022745) and GAPDH (HQP064347) purchased from GeneCopoeia (USA). The primers used for putative FOXC1 binding site 2 were as follows: forward, 5'-AAAAAATTGGAGGC TGCTT-3'; reverse, 5' -CCAAAGAAAAATCCCCACA-3'. Fold change was calculated by the $\triangle \triangle \mathrm{Ct}$ method.

\section{Western blotting}

RIPA (Beyotime, China) buffer supplemented with phosphatase inhibitor (Beyotime) and a Nuclear Protein Extraction Kit (Beyotime) were used to extract total and nuclear proteins from NSCLC cells. The extracted proteins were transferred to PVDF membranes after fractionation by SDS-PAGE. After blocking in 5\% milk for $2 \mathrm{~h}$, the PVDF membranes were incubated at $4{ }^{\circ} \mathrm{C}$ overnight with a specific antibody. Protein bands were visualized using ExPlus ECL (ZOMANBIO) with a MicroChemi system (DNR, Israel). The primary antibody against glycogen synthase kinase 3 beta (GSK3 $\beta$ ) (12456 T) was purchased from Cell Signaling Technology (USA), and primary antibodies against FOXC1 (ab5079), LMNB1 (ab133741), ABCG2 (ab207732), SOX2 (ab92494), Oct4 (ab181557), phosphoGSK3 $\beta$ (pGSK3 $\beta$ ) (ab75814) and NANOG (ab109250) were purchased from Abcam (USA). The primary antibody against GAPDH (60004-1-Ig) was purchased from Proteintech (China), and the primary antibody against beta-actin (A01011-1) was purchased from Abbkine (China).

\section{Establishment of stable cell lines}

A short hairpin RNA against FOXC1 (shFOXC1)-expressing plasmid HSH005629-33-LVRU6rLP (GeneCopoeia) or FOXC1-expressing plasmid CS-X0042-Lv217-01 (GeneCopoeia) was packaged into lentivirus following the user manual of the Lenti-Pac HIV Expression Packaging kit (GeneCopoeia). NSCLC cells were infected 
with lentiviral particles for $12 \mathrm{~h}$. FOXC1-knockdown (A549-LV-shFOXC1 and PC9/G-LV-shFOXC1) and overexpressing (NCI-H1299-LV-FOXC1 and PC9-LV-FOXC1) cell lines were obtained by selection with puromycin. Beta-catenin-overexpressing (A549-shFOXC1-LV-beta-catenin and PC9/G-shFOXC1-LV-beta-catenin) and knockdown (NCI-H1299-FOXC1-LV-shbeta-catenin and PC9FOXC1-LV-shbeta-catenin) cell lines were established using a similar procedure. The beta-catenin-expressing plasmid EX-T0573-Lv220 and the shbeta-catenin-expressing plasmid HSH054811-4-LVRU6GP were purchased from GeneCopoeia. The shFOXC1 target sequence was GGGAAACTGTATTAATCTTAT and the shbeta-catenin target sequence was GCTGATATT GATGGACAGTAT.

\section{Flow cytometric analysis}

A sample of $1 \times 10^{6}$ cells was washed twice with PBS supplemented with $0.5 \%$ BSA and 2 mM EDTA and incubated in diluted CD133-PE antibody solution (Miltenyi Biotec, Germany) for $10 \mathrm{~min}$. After washing the cells twice, the percentage of $\mathrm{CD}_{133^{+}}$cells was analyzed by flow cytometry (BD, USA).

\section{Sphere-formation analysis}

A total of $5 \times 10^{3}$ cells were seeded into 6-well ultra low-attachment plates and incubated in DMEM/F12 (Gibco, USA) supplemented with EGF $(20 \mathrm{ng} / \mathrm{mL}$, Peprotech, USA), FGF-basic (20 ng/mL, Gibco) and B27 (20 $\mu \mathrm{l} / \mathrm{mL}$, Gibco) for two weeks. The number of spheres (diameter $>100 \mu \mathrm{m})$ was counted under an electron microscope (Nikon, Japan).

\section{Xenograft assay}

BALB/c nude mice, aged 5 weeks and weighing 20-22 g, were purchased from Hunan SJA Laboratory Animal Co., Ltd. (China). A series of NSCLC cells $\left(5 \times 10^{5}, 5 \times\right.$ $10^{4}$ and $5 \times 10^{3}$ ) were suspended in Matrigel (BD, USA) and subcutaneously inoculated into the mice. The tumor volume was calculated using the formula (length $x$ width $\left.^{2}\right) / 2$.

\section{Immunohistochemical staining}

FOXC1 and beta-catenin protein levels in xenograft tumors were detected using anti-FOXC1 (ab5079) and anti-beta-catenin (Sc-7199) antibodies following standard protocols for immunohistochemical staining.

\section{Cell viability assay}

Cells $\left(5 \times 10^{3}\right)$ were incubated in culture medium supplemented with serial concentrations of cisplatin, docetaxel or gefitinib for $48 \mathrm{~h}$. A cell counting kit (ZOMANBIO) was used to measure cell viability.

\section{Apoptosis assay}

A total of $1.5 \times 10^{5}$ cells were incubated in culture medium supplemented with cisplatin, docetaxel or gefitinib for $48 \mathrm{~h}$. The percentage of apoptotic cells was analyzed using an Annexin V-FITC apoptosis analysis kit (Sungene Biotech, China) following the user manual.

\section{Luciferase reporter assay}

The full-length FOXC1 cDNA was cloned into the pIRES2 vector (Clontech, USA) to construct FOXC1-expressing plasmid pIRES2-FOXC1. The wild-type or mutant betacatenin promoter $[(-1369 /+163)$ beta-catenin, relative to the transcriptional start site] was cloned into the pGL3 plasmid (Promega, USA) to construct beta-catenin reporter plasmid pGL3-beta-catenin. $293 \mathrm{~T}$ cells were transfected with pIRES2-FOXC1, pGL3-beta-catenin and Renilla luciferase reporter PRL-TK plasmids using Lipofectamine 3000 (Invitrogen). After $48 \mathrm{~h}$, a dual-luciferase reporter assay system (Promega) was employed to measure luciferase activity.

\section{Chromatin immunoprecipitation (ChIP)}

Formaldehyde $(1 \%)$ was used to crosslink cells $\left(4 \times 10^{6}\right)$ at $4{ }^{\circ} \mathrm{C}$ for $12 \mathrm{~min}$. Glycine $(0.125 \mathrm{~mol} / \mathrm{L})$ was added to stop the crosslinking, and chromatin was sheared into small fragments using sonication. The anti-FOXC1 antibody (ab5079) and protein G beads were applied to pull down the target protein, and proteinase $\mathrm{K}$ was used to digest proteins at $45{ }^{\circ} \mathrm{C}$ for $50 \mathrm{~min}$. Target proteinbound DNA was harvested and purified using HSYBR qPCR Mix (ZOMANBIO).

\section{Statistical analysis}

Quantitative results are presented as the mean \pm standard deviation (SD). Student's t-test and the $\chi^{2}$ test were utilized to determine statistical significance. The KaplanMeier method and log-rank test were used in survival analyses. $p<0.05$ was considered statistically significant.

\section{Results \\ FOXC1 expression is elevated in NSCLC tissues and negatively correlates with survival probability}

We analyzed FOXC1 expression in NSCLC based on information in the Cancer Genome Atlas (TCGA) database on UALCANC [35] and found elevated FOXC1 expression in lung adenocarcinoma (LUAD) and lung squamous cell carcinoma (LUSC) compared to normal lung tissues (Fig. 1a). We also examined the relationship between FOXC1 expression and NSCLC patient survival on Human Protein Atlas [36], which revealed an inverse correlation between FOXC1 expression and survival in LUAD and LUSC patients (Fig. 1b). 

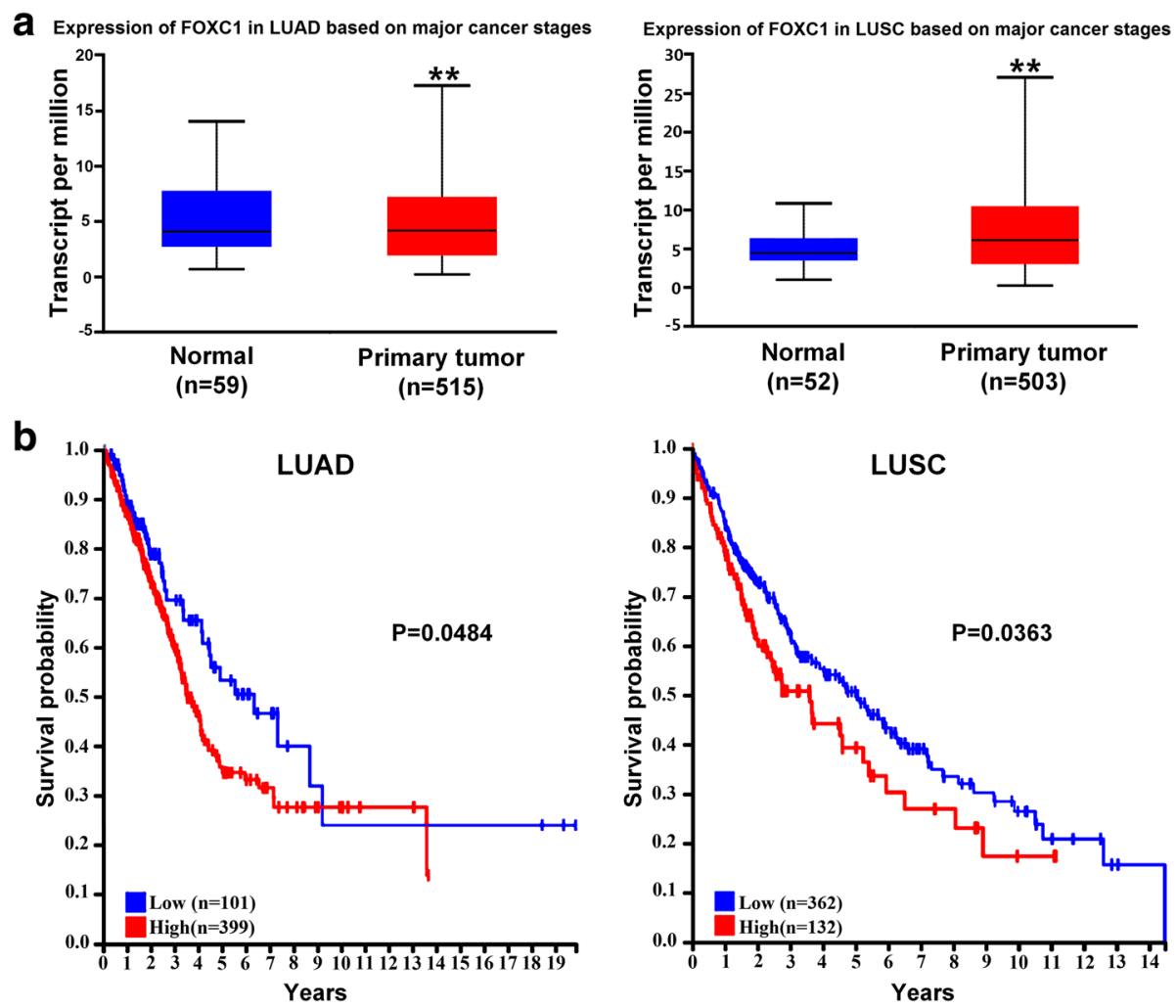

Fig. 1 FOXC1 expression is elevated in NSCLC tissues and negatively correlates with survival probability. a FOXC1 expression levels in LUAD and LUSC tissues and normal lung tissues in TCGA were analyzed on UALCANC. $\mathbf{b}$ Kaplan-Meier analyses of survival probabilities of LUAD and LUSC patients were performed on Human Protein Atlas. The log-rank test was used to calculate $p$ values. ${ }^{* *} P<0.01$

FOXC1 enhances stemness of NSCLC cells in vitro

We found FOXC1 to be widely expressed in NSCLC cells, and FOXC1 expression was significantly higher in gefitinib-resistant PC9/G cells than in gefitinib-sensitive PC9 cells (Fig. 2a). High (A549 and PC9/G) and low (NCI-H1299 and PC9) FOXC1-expressing cell lines were used for further studies. We established an A549LV-shFOXC1 stable cell line with stable knockdown of FOXC1 expression (Fig. 2b), and a NCI-H1299-LVFOXC1 stable cell line with constant FOXC1 expression (Fig. 2c). FOXC1 knockdown reduced the percentage of $\mathrm{CD} 133^{+}$cells (Fig. 2d), inhibited sphere formation (Fig. 2f) and downregulated mRNA and protein levels of stemness-related genes (SOX2, Oct4, NANOG and ABCG2) (Fig. 2h). Conversely, FOXC1 overexpression increased the $\mathrm{CD}_{133^{+}}$cell percentage (Fig. 2e), promoted sphere formation (Fig. 2g) and upregulated mRNA and protein levels of SOX2, Oct4, NANOG and ABCG2 (Fig. 2i).

\section{FOXC1 enhances tumorigenicity of NSCLC cells in vivo}

To investigate whether FOXC1 influences NSCLC cell tumorigenicity in vivo, we subcutaneously inoculated a series of NSCLC cells $\left(5 \times 10^{5}, 5 \times 10^{4}\right.$ and $\left.5 \times 10^{3}\right)$ into
BALB/c nude mice. FOXC1 knockdown decreased tumor incidence rate (Fig. 3a), tumor volume (Fig. 3c and e) and tumor weight (Fig. 3g), whereas, FOXC1 overexpression had the opposite effects (Fig. 3b, d, f and h).

\section{FOXC1 confers drug resistance in NSCLC cells}

As the presence of CSCs is one of the major causes of resistance to therapy [37], we investigated whether FOXC1 is involved in drug resistance in NSCLC. Cisplatin and docetaxel are widely used cytotoxic anti-cancer agents in NSCLC treatment $[38,39]$. FOXC1 knockdown enhanced the cell killing effects of cisplatin and docetaxel on A549 cells (Fig. 4a and b) and increased the percentage of apoptotic cells (Fig. 4e). In contrast, FOXC1 overexpression attenuated cisplatin and docetaxel-mediated killing of NCI-H1299 cells (Fig. 4c and d) and reduced apoptotic cell percentage (Fig. 4f). Gefitinib is a classic molecularly targeted anti-NSCLC agent [40] and FOXC1 expression was significantly higher in the gefitinib-resistant PC9/G cell line than in the gefitinib-sensitive parental PC9 cell line. We established a PC9/G-LV-shFOXC1 stable cell line, in which FOXC1 expression was stably downregulated in PC9/G cells (Fig. 4g), and a PC9-LV-FOXC1 stable cell line, in which FOXC1 expression was stably 


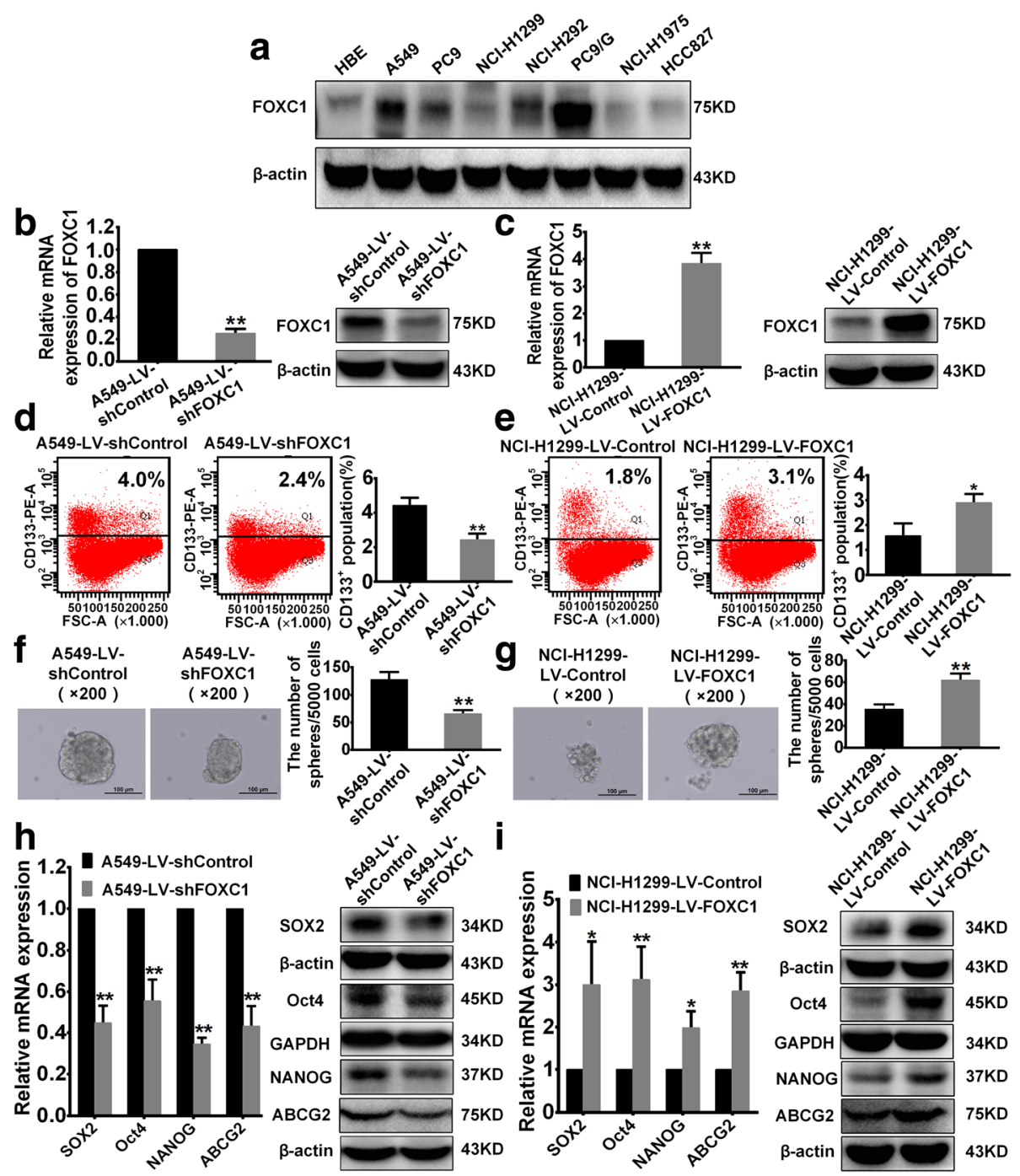

Fig. 2 FOXC1 induces stemness of NSCLC cells in vitro. a FOXC1 protein levels in NSCLC cells were detected by western blotting. $\mathbf{b}$ and $\mathbf{c}$ FOXC1 mRNA and protein levels were stably downregulated in A549 cells and upregulated in NCl-H1299 cells. $\mathbf{d}$ and e The percentage of CD133 ${ }^{+}$cells was analyzed by flow cytometry. $\mathbf{f}$ and $\mathbf{g}$ Representative images (left) and numbers (right) of spheres (diameter $>100 \mu \mathrm{m}$ ). $\mathbf{h}$ and $\mathbf{i}$ Protein and mRNA levels of SOX2, Oct4, NANOG and ABCG2. All experiments were independently repeated three times. The bar graph presents the mean \pm SD. ${ }^{* P}<0.05,{ }^{* * P}<0.01$

upregulated in PC9 cells (Fig. 4i). FOXC1 knockdown enhanced PC9/G cell killing by gefitinib (Fig. 4h) and increased the percentage of gefitinib-induced apoptotic cells (Fig. 4k), whereas FOXC1 overexpression attenuated the inhibitory effect of gefitinib on PC9 cell viability (Fig. 4j) and reduced the percentage of gefitinib-induced apoptotic cells (Fig. 4l).

\section{Beta-catenin mediates FOXC1-induced CSC-like properties in NSCLC}

Wnt/beta-catenin is an important signaling pathway for regulating CSCs [41]. Although alteration of FOXC1 expression did not cause significant changes in the levels of GSK3 $\beta$ and pGSK3 $\beta$ (Fig. 5a and b), FOXC1 knockdown reduced beta-catenin mRNA levels as well as levels of total and nuclear beta-catenin protein (Fig. 5a). FOXC1 knockdown also downregulated beta-catenin protein levels in xenograft tumors (Fig. 5c). FOXC1 overexpression increased beta-catenin mRNA levels and total and nuclear beta-catenin protein levels (Fig. 5b). Moreover, FOXC1 overexpression upregulated beta-catenin protein levels in xenograft tumors (Fig. 5d). Luciferase reporter assays showed that FOXC1 significantly enhanced beta-catenin promoter activity (Fig. 5e). Because of the conserved winged helix DNA-binding domain in FOX proteins [7], FOX transcription factor binding sites (BSs) share a 


\section{a}

\begin{tabular}{lccc}
\hline \multicolumn{4}{c}{ Cell number inoculated } \\
\cline { 2 - 4 } $5 \times 10^{5}$ & $5 \times 10^{4}$ & $5 \times 10^{3}$ \\
\hline A549-LV- & $8 / 8$ & $7 / 8$ & $4 / 8$ \\
shControl & & \\
A549-LV- & $7 / 8$ & $6 / 8$ & $1 / 8$ \\
shFOXC1 & $7 / 8$ &
\end{tabular}

C $5 \times 10^{5}$ A549-LV-shControl

$5 \times 10^{4} \begin{aligned} & \text { A549-LV-shControl } \\ & \text { A549-LV-shFoxC1 }\end{aligned}$ e$$
\text { है }
$$

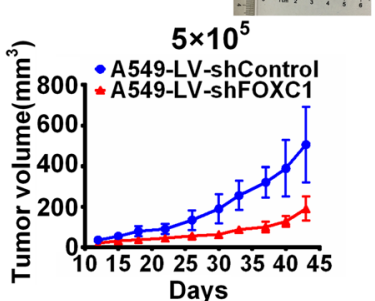

f $5 \times 10^{5}$

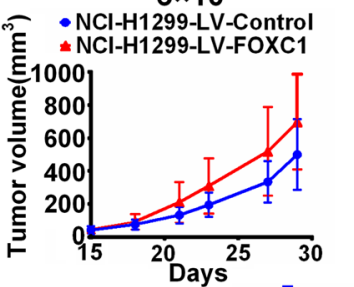

9 פิ0.5 A549-LV-shFOXC1
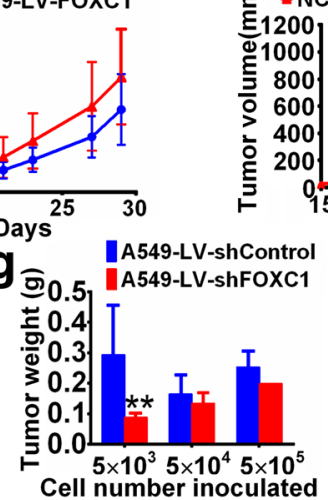

혼 800

ํㅡㄴ 600 b

\begin{tabular}{lccc}
\hline \multicolumn{4}{c}{ Cell number inoculated } \\
\cline { 2 - 4 } $5 \times 10^{5}$ & $5 \times 10^{4}$ & $5 \times 10^{3}$ \\
\hline $\begin{array}{l}\text { NCl-H1299- } \\
\text { LV-Control }\end{array}$ & $7 / 8$ & $4 / 8$ & $1 / 8$ \\
NCl-H1299- & $8 / 8$ & $6 / 8$ & $3 / 8$ \\
\hline
\end{tabular}

d

NCI-H1299-LV-Control

$5 \times 10^{5}{ }_{\mathrm{NCI}-\mathrm{H} 1299-\mathrm{LV}-\mathrm{FOXC1}}$

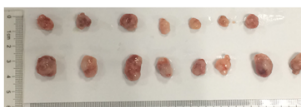

$5 \times 10^{4} \stackrel{\mathrm{NCl}-\mathrm{H} 1299-\mathrm{LV}-\mathrm{Control}}{\mathrm{NCl}-\mathrm{H} 1299-\mathrm{LV}-\mathrm{FOXC1}}$

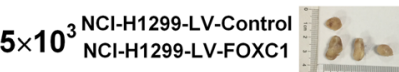

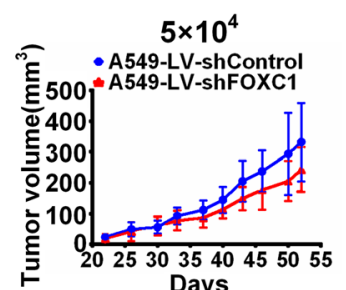

Days

$5 \times 10^{4}$

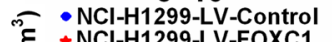

ENCI-H1299-LV-FOXC1

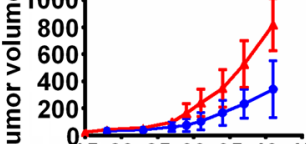

\section{$5 \times 10^{3}$}

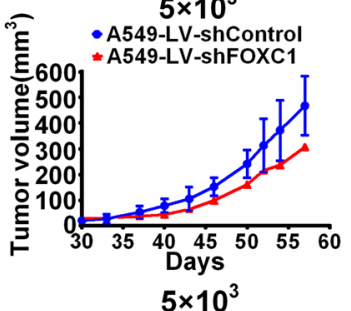

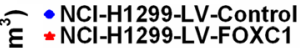

$E$ NCl

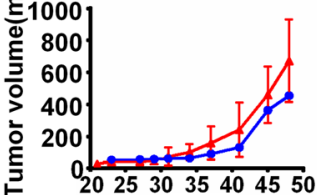

h

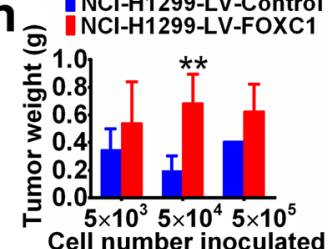

Fig. 3 FOXC1 enhances the tumorigenicity of NSCLC cells in vivo. A series of cells $\left(5 \times 10^{5}, 5 \times 10^{4}\right.$ and $\left.5 \times 10^{3}\right)$ were subcutaneously inoculated into BALB/c nude mice ( $n=8 /$ group). $\mathbf{a}$ and $\mathbf{b}$ The tumor incidence of each group. $\mathbf{c}-\mathbf{f}$ Images and growth curves of tumor xenografts. $\mathbf{g}$ and $\mathbf{h}$ Histograms show the tumor weights of each group. The bar graph presents the mean \pm SD. ${ }^{* *} P<0.01$

consensus sequence: WAARYAAAYW $(\mathrm{R}=\mathrm{G}$ or $\mathrm{A}, \mathrm{Y}=\mathrm{C}$ or $\mathrm{T}, \mathrm{W}=\mathrm{T}$ or $\mathrm{A})[42,43]$. Analysis of the beta-catenin promoter sequence using TRANSFAC and JASPAR revealed three putative FOXC1 BSs: BS1, GTTCGTTTGTT $[(-1268 /-1258)$ beta-catenin, relative to the transcriptional start site]; BS2, TCTATAAACAT $[(-997 /-987)$ betacatenin]; BS3, TTATTTGTTCA $[(-821 /-811)$ betacatenin]. Although mutations in BS1 and BS3 did not significantly affect luciferase activity, BS2 mutation decreased FOXC1-induced luciferase activity (Fig. 5f). ChIP and real-time PCR assays confirmed the binding of FOXC1 to BS2 in NSCLC cells (Fig. 5g).

To investigate whether beta-catenin mediates FOXC1induced CSC-like properties, LV-beta-catenin lentivirus was used to upregulate beta-catenin expression in A549LV-shFOXC1 cells (Fig. 6a), and LV-shbeta-catenin lentivirus was used to knockdown beta-catenin expression in NCI-H1299-LV-FOXC1 cells (Fig. 6b). Beta-catenin overexpression increased $\mathrm{CD}_{133^{+}}$cell percentage (Fig. 6c), promoted sphere formation (Fig. 6e) and upregulated levels of SOX2, Oct4, NANOG and ABCG2 proteins (Fig. 6g) in FOXC1-knockdown cells. Conversely, beta-catenin knockdown decreased the percentage of $\mathrm{CD}_{133^{+}}$cells (Fig. 6d), inhibited sphere formation (Fig. 6f) and downregulated protein levels of SOX2, Oct4, NANOG and ABCG2 (Fig. 6h) in FOXC1-overexpressing cells. Moreover, beta-catenin overexpression attenuated the inhibitory effects of 

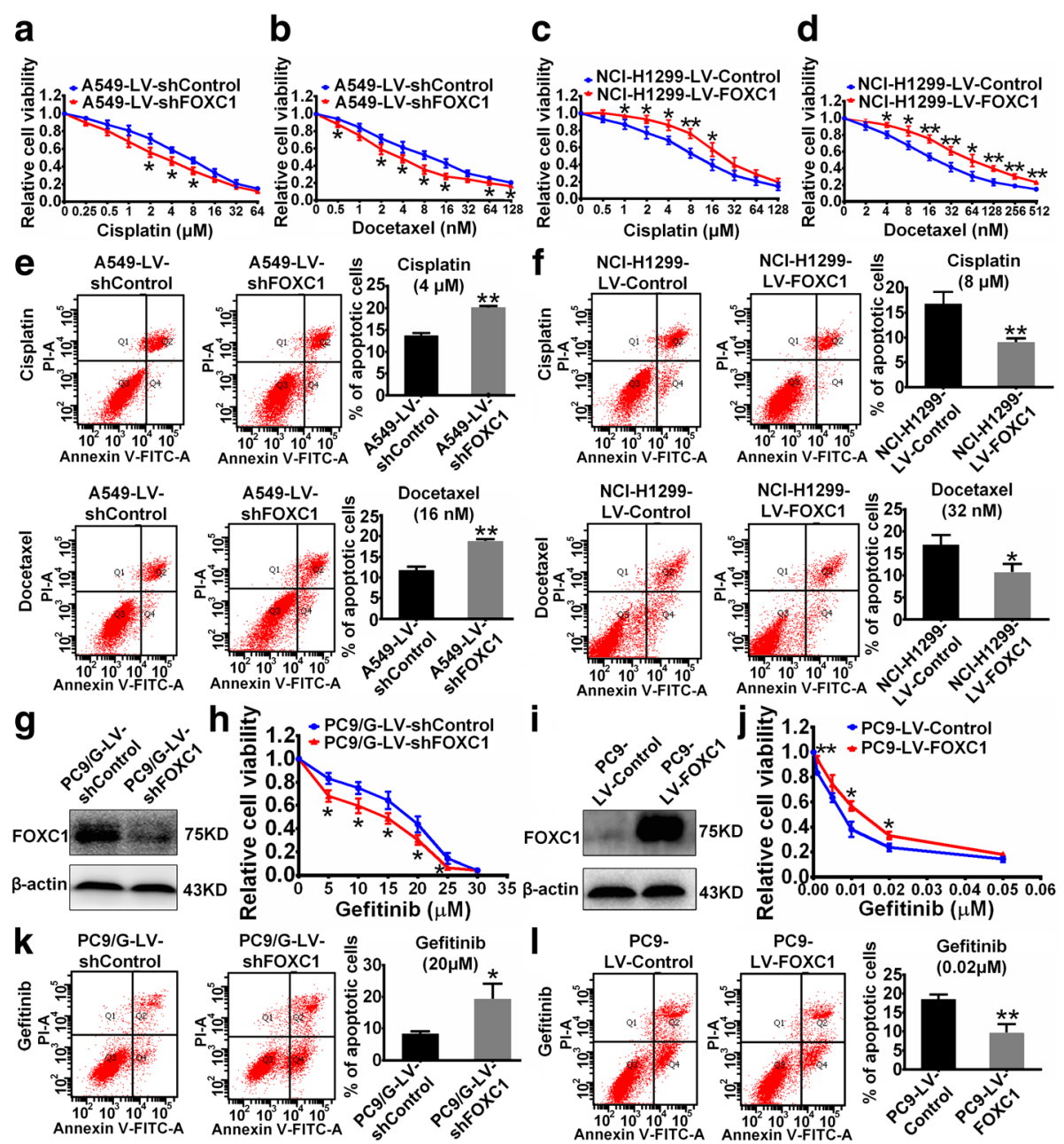

Gefitinib $(\mu \mathrm{M})$

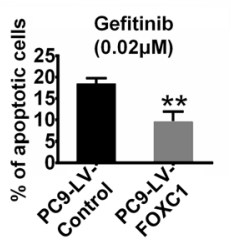

Fig. 4 FOXC1 induces resistance to cisplatin, docetaxel and gefitinib. a-d Cell viability was detected after cells were treated with cisplatin or docetaxel at the indicated concentrations. e and $\mathbf{f}$ Percentage of apoptotic cells, including early apoptotic cells (Q2) and late apoptotic cells (Q4), was determined by flow cytometric analysis after treatment with cisplatin or docetaxel. $\mathbf{g}$ and $\mathbf{i}$ FOXC1 protein levels were stably downregulated in PC9/G cells and upregulated in PC9 cells. $\mathbf{h}$ and $\mathbf{j}$ Cell viability was detected after cells were treated with gefitinib at the indicated concentrations. $\mathbf{k}$ and I Percentage of apoptotic cells was determined after treatment with gefitinib. All experiments were independently repeated three times. The bar graph presents the mean $\pm \mathrm{SD}$. ${ }^{*} P<0.05,{ }^{*} P<0.01$

cisplatin, docetaxel and gefitinib on FOXC1-knockdown cell viability (Fig. 7a, c and e), whereas beta-catenin knockdown enhanced the inhibitory effects of drugs on the viability of FOXC1-overexpressing cells (Fig. 7b, d and $f$ ).

\section{Discussion}

Elevated FOXC1 expression in NSCLC tissues and inverse correlation between FOXC1 expression and patient survival indicate that FOXC1 may be a negative prognostic factor in NSCLC. In this study, we found that FOXC1 is involved in the regulation of CSC-like properties, an important factor contributing to tumorigenesis and progression of NSCLC [6]. CD133 is a specific cell surface marker for CSCs in NSCLC, and CD133 ${ }^{+}$cells exhibit stem-like and highly tumorigenic features $[44,45]$. Our results showed that FOXC1 knockdown decreased the percentage of $\mathrm{CD}_{133^{+}}$cells. Moreover, sphere-formation assay revealed that FOXC1 knockdown inhibited self-renewal ability, one of the most important characteristics of CSCs [4]. Oct4, NANOG, SOX2 and ABCG2 are essential stemness-related genes that maintain CSC-like properties in NSCLC [46-48], and FOXC1 knockdown decreased expression of these genes. Efficient tumorigenicity is a definitive feature of CSCs [49], and FOXC1 knockdown suppressed NSCLC cell tumorigenicity in vivo. Conversely, FOXC1 overexpression enhanced cancer stemness. These results indicate that $\mathrm{FOXC1}$ is an important factor promoting cancer stemness in NSCLC. 


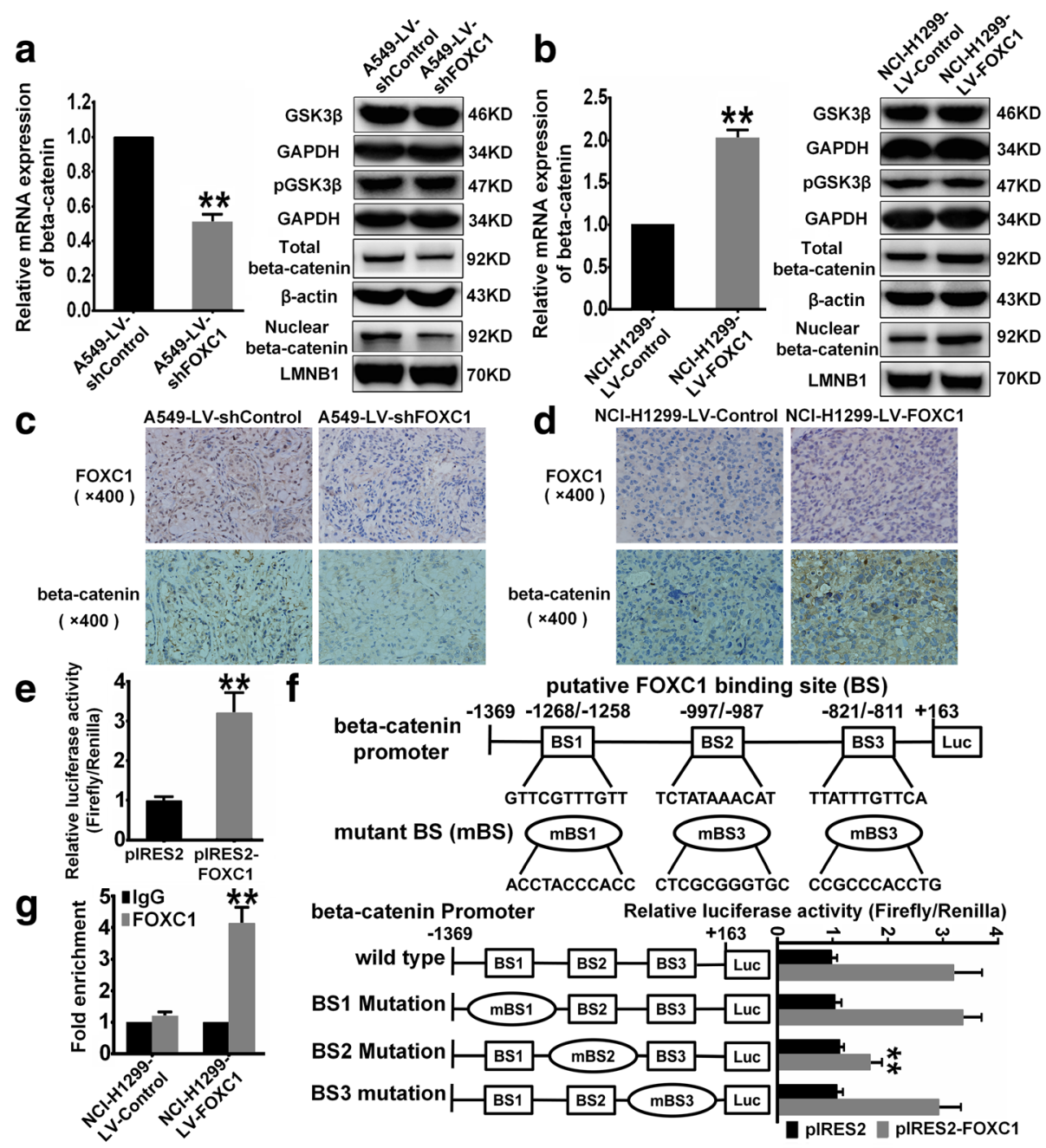

Fig. 5 FOXC1 promotes beta-catenin expression by enhancing the activity of beta-catenin promoter. $\mathbf{a}$ and $\mathbf{b}$ Real-time PCR and western blotting were used to detect changes in beta-catenin mRNA, GSK3 $\beta$, PGSK3 $\beta$ and total and nuclear beta-catenin protein levels induced by FOXC1 knockdown or overexpression. $\mathbf{c}$ and $\mathbf{d}$ Representative immunohistochemical staining of FOXC1 and beta-catenin in xenograft tumors. e Luciferase reporter assays showed that FOXC1 significantly enhanced beta-catenin promoter activity. $\mathbf{f}$ Putative FOXC1 binding sites in the beta-catenin promoter and mutations in corresponding binding sites. Schematic representations of wild-type and mutant beta-catenin promoters (left) and the corresponding relative luciferase activity (right) are shown. $\mathbf{g}$ ChIP and real-time PCR assays were used to investigate the binding of FOXC1 to the putative binding site BS2. All experiments were independently repeated three times. The bar graph presents the mean \pm SD. ${ }^{* *} P<0.01$

Drug resistance, a major problem for NSCLC treatment $[50,51]$, is another essential property of CSCs, which resist therapy by enhancing membrane transporter activity and activating anti-apoptotic pathways. Conventional anti-cancer drugs kill most tumor cells but not CSCs, and surviving CSCs re-establish tumors [37]. Cisplatin and docetaxel are broadly employed cytotoxic anti-cancer agents in NSCLC $[38,39]$. We found FOXC1 knockdown promoted NSCLC cell killing induced by cisplatin and docetaxel, whereas FOXC1 overexpression compromised this effect. These results indicate that FOXC1 plays a pivotal role in mediating the sensitivity of
NSCLC cells to cisplatin and docetaxel and that it is a potential target for overcoming chemotherapy resistance in NSCLC. The molecularly targeted agent gefitinib, an epidermal growth factor receptor-tyrosine kinase inhibitor (EGFR-TKI), has been widely used in NSCLC treatment and it can dramatically improve patient survival. However, resistance to gefitinib severely reduces its clinical efficacy [52]. We detected higher levels of FOXC1 protein in gefitinib-resistant PC9/G cells than in gefitinib-sensitive PC9 cells. Knockdown of FOXC1 expression sensitized cells to gefitinib, whereas its overexpression conferred resistance to gefitinib. These results indicate that FOXC1 is a 


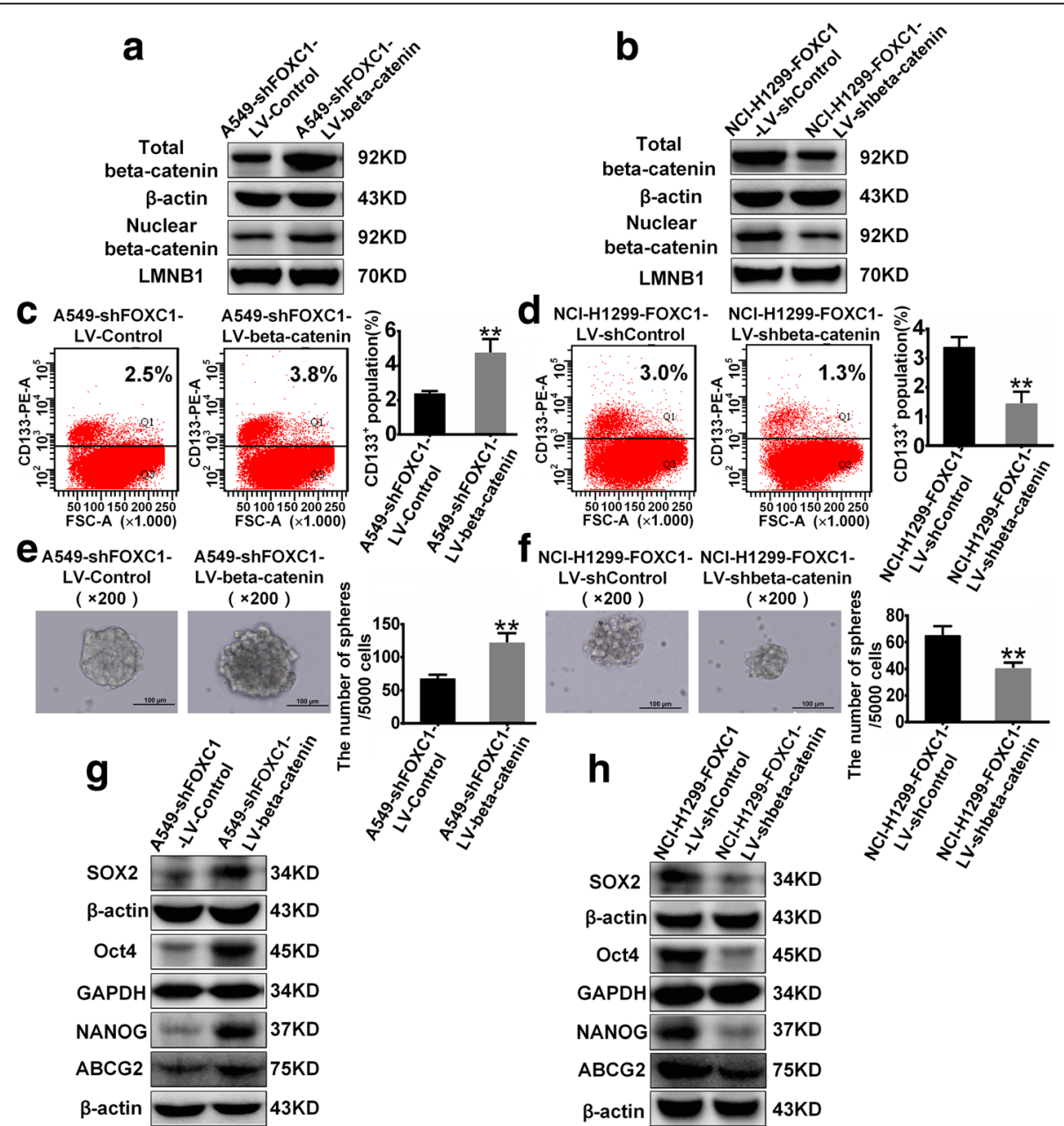

Fig. 6 Beta-catenin mediates FOXC1-induced cancer stemness in NSCLC. a and $\mathbf{b}$ Total and nuclear beta-catenin protein levels were stably upregulated in A549-LV-shFOXC1 cells and downregulated in NCl-H1299-LV-FOXC1 cells. $\mathbf{c}$ and $\mathbf{d}$ The percentage of CD133 $3^{+}$cells was analyzed by flow cytometry. e and $\mathbf{f}$ Representative images (left) and numbers (right) of spheres (diameter $>100 \mu \mathrm{m}$ ). $\mathbf{g}$ and $\mathbf{h}$ Protein levels of SOX2, Oct4, NANOG and ABCG2. All experiments were independently repeated three times. The bar graph presents the mean \pm SD. ${ }^{* *} P<0.01$

candidate biomarker and therapeutic target for overcoming EGFR-TKI resistance.

Finally, we explored the molecular mechanism underlying the promoting effects of FOXC1 on CSC-like properties. The Wnt/beta-catenin pathway is critical for regulating CSC-like properties. After activation of this pathway, increased amount of beta-catenin protein in the nucleus forms complexes with TCF/LEF to regulate target gene expression [41]. In NSCLC cells, FOXC1 knockdown reduced beta-catenin mRNA levels as well as total and nuclear beta-catenin protein levels. FOXC1 knockdown also downregulated beta-catenin protein levels in xenograft tumors. Moreover, FOXC1 knockdown decreased expression of Oct4, NANOG, SOX2 and ABCG2, which are important downstream target genes of beta-catenin in regulating cancer stemness [53-56]. In contrast, FOXC1 overexpression resulted in opposite effects. Luciferase reporter assays revealed that FOXC1 promoted beta-catenin expression by enhancing beta-catenin promoter activity. ChIP and real-time PCR assays confirmed the binding of FOXC1 to the beta-catenin promoter $(-997 /-987)$. Beta-catenin is considered to be a major contributor to high metastatic potential, a characteristic of CSCs [41, 57], and FOXC1 has been proven to promote metastasis in NSCLC $[18,19]$. These observations are consistent with our finding that FOXC1 promotes beta-catenin expression. Furthermore, beta-catenin overexpression rescued the inhibited CSClike properties induced by FOXC1 knockdown, whereas beta-catenin knockdown attenuated the enhanced CSClike properties induced by FOXC1 overexpression. These results indicate that beta-catenin mediates the promoting effects of FOXC1 on CSC-like properties in NSCLC. 

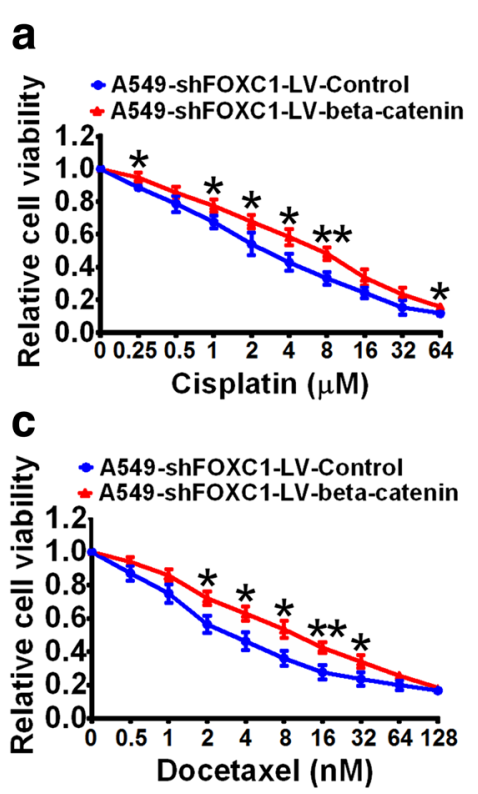

b

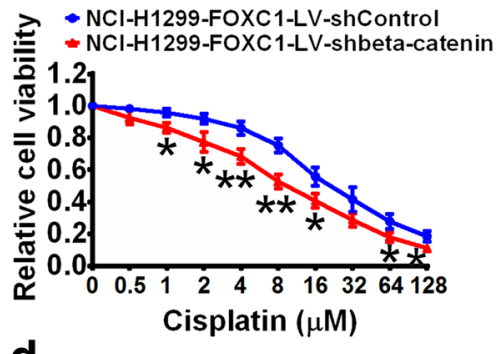

d
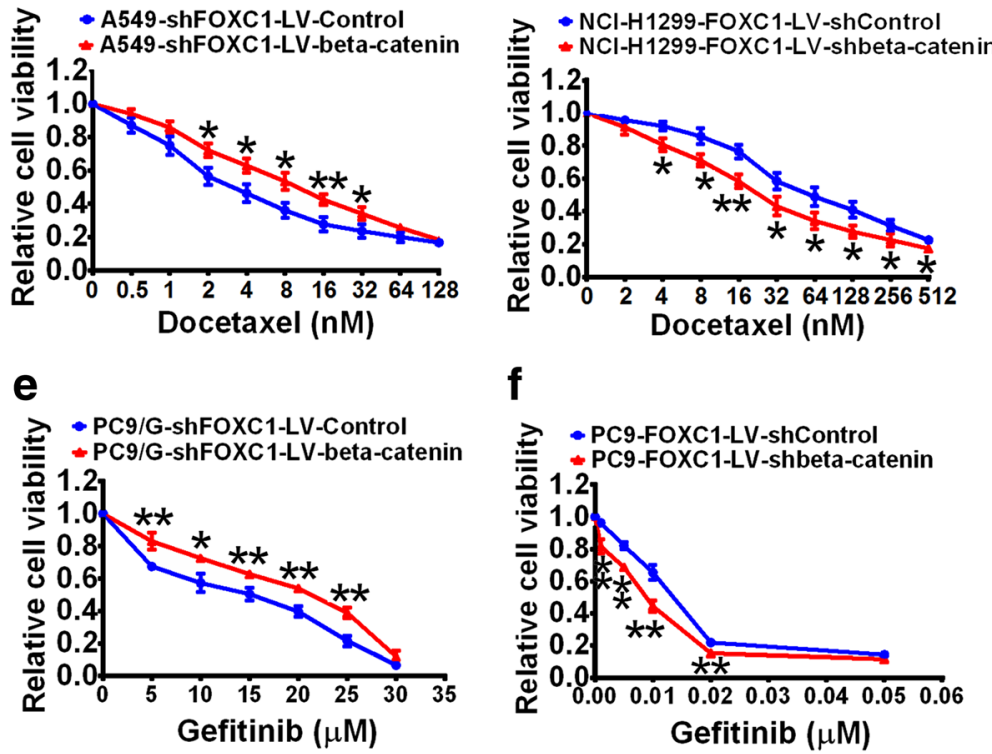

f

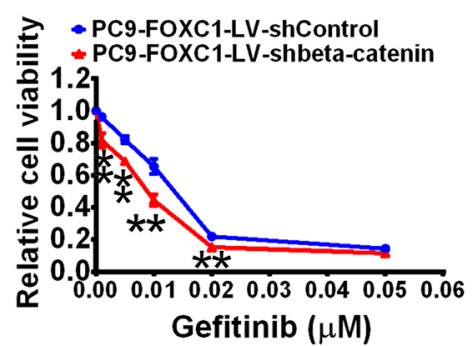

Fig. 7 Beta-catenin mediates FOXC1-induced drug resistance in NSCLC. a, $\mathbf{c}$ and e Beta-catenin overexpression attenuated the inhibitory effects of cisplatin, docetaxel and gefitinib on the viability of FOXC1-knockdown cells. $\mathbf{b}$, $\mathbf{d}$ and $\mathbf{f}$ Beta-catenin knockdown enhanced the cell killing effects of cisplatin, docetaxel and gefitinib on FOXC1-overexpressing cells. ${ }^{*} P<0.05,{ }^{* *} P<0.01$

\section{Conclusions}

In conclusion, this study is the first to demonstrate that FOXC1 contributes to CSC-like properties in NSCLC, including increased $\mathrm{CD}_{133^{+}}$cell population and stemness-related gene expression, enhanced selfrenewal ability and tumorigenicity and induction of drug resistance, by promoting beta-catenin expression. These findings indicate that FOXC1 is a potential molecular target for anti-CSC-based therapies in NSCLC.

\section{Abbreviations}

ABCG2: ATP-binding cassette subfamily G member 2; ChIP: Chromatin immunoprecipitation; CSC: Cancer stem cell; EGFR-TKI: Epidermal growth factor receptor-tyrosine kinase inhibitor; FOXC1: Forkhead box C1;

GSK3 $\beta$ : Glycogen synthase kinase 3 beta; NSCLC: Non-small cell lung cancer; ShRNA: Short hairpin RNA; TCGA: The Cancer Genome Atlas

\section{Acknowledgments}

We are grateful to Shunchang Zhou for technical assistance in animal experiments.

\section{Funding}

This work was supported by grants from the National Natural Science Foundation of China [Grant number: 81672947], Natural Science Foundation of Hubei Province for Distinguished Young Scholars [Grant number: 2018CFA032], Huazhong University of Science and Technology funds [Grant number: 2016YXZD035 and 2017KFKJXX004] and Wuhan Science and Technology Research Project [Grant number: 2017060201010149].

\section{Availability of data and materials}

The gene expression and survival datasets of NSCLC patients analysed during the current study are available in UALCANC and Human Protein Atlas (http://ualcan.path.uab.edu/analysis.html, https://www.proteinatlas.org/). All data generated during this study are included in this published article.

\section{Authors' contributions}

SSC and ZW performed the experiments. SSC drafted the manuscript. ZW performed the statistical analysis. XJG, WJH and YC analyzed the gene expression and survival data of NSCLC patients and edited the manuscript. $\mathrm{HC}$ and RX designed this study and revised the manuscript. All authors approved the final manuscript.

Ethics approval and consent to participate

All the analyses involving human data were approved by the Ethics Committee of Tongii Medical College, Huazhong University of Science and Technology (IORG No: IORG0003571). All the animal experimental procedures 
were conformed to the Institutional Animal Care and Use Committee of Tongji Medical College of Huazhong University of Science and Technology.

\section{Consent for publication}

Not applicable.

\section{Competing interests}

The authors declare that they have no competing interests.

\section{Publisher's Note}

Springer Nature remains neutral with regard to jurisdictional claims in published maps and institutional affiliations.

\section{Author details}

'Department of Pharmacology, School of Basic Medicine, Tongji Medical College, Huazhong University of Science and Technology, Wuhan 430030, Hubei, China. ${ }^{2}$ The Key Laboratory for Drug Target Researches and Pharmacodynamic Evaluation of Hubei Province, Wuhan 430030, Hubei, China.

Received: 21 May 2018 Accepted: 25 August 2018

\section{Published online: 06 September 2018}

\section{References}

1. Torre LA, Bray F, Siegel RL, Ferlay J, Lortet-Tieulent J, Jemal A. Global cancer statistics, 2012. CA Cancer J Clin. 2015;65:87-108.

2. Hirsch FR, Scagliotti GV, Mulshine JL, Kwon R, Curran WJ, Wu YL, Paz-Ares L. Lung cancer: current therapies and new targeted treatments. Lancet. 2017; 389:299-311.

3. Ma Z, Yang Y, Di S, Feng X, Liu D, Jiang S, Hu W, Qin Z, Li Y, LV J, et al. Pterostilbene exerts anticancer activity on non-small-cell lung cancer via activating endoplasmic reticulum stress. Sci Rep. 2017:7:8091.

4. Reya T, Morrison SJ, Clarke MF, Weissman IL. Stem cells, cancer, and cancer stem cells. Nature. 2001:414:105-11.

5. Batlle E, Clevers H. Cancer stem cells revisited. Nat Med. 2017;23:1124-34

6. Wu XD, Chen H, Wang XD. Can lung cancer stem cells be targeted for therapies? Cancer Treat Rev. 2012;38:580-8.

7. Kaestner $\mathrm{KH}$, Knochel W, Martinez DE. Unified nomenclature for the winged helix/forkhead transcription factors. Genes Dev. 2000;14:142-6.

8. Benayoun BA, Caburet S, Veitia RA. Forkhead transcription factors: key players in health and disease. Trends Genet. 2011;27:224-32.

9. Xin Z, Ma Z, Hu W, Jiang S, Yang Z, Li T, Chen F, Jia G, Yang Y. FOXO1/3: potential suppressors of fibrosis. Ageing Res Rev. 2018;41:42-52.

10. Wang J, Li W, Zhao Y, Kang FW, Zheng X, Pang X, Du G. Members of FOX family could be drug targets of cancers. Pharmacol Ther. 2018:181:183-96.

11. Ma Z, Xin Z, Hu W, Jiang S, Yang Z, Yan X, Li X, Yang Y, Chen F. Forkhead box O proteins: crucial regulators of cancer EMT. Semin Cancer Biol. 2018; $50: 21-31$.

12. Jiang S, Li T, Yang Z, Hu W, Yang Y. Deciphering the roles of FOXO1 in human neoplasms. Int J Cancer. 2018; https://doi.org/10.1002/ijc.31338.

13. Jiang S, Yang Z, Di S, Hu W, Ma Z, Chen F, Yang Y. Novel role of forkhead box $\mathrm{O} 4$ transcription factor in cancer: bringing out the good or the bad. Semin Cancer Biol. 2018;50:1-12.

14. Yamaguchi N, Nakayama Y, Yamaguchi N. Down-regulation of Forkhead box protein A1 (FOXA1) leads to cancer stem cell-like properties in tamoxifen-resistant breast cancer cells through induction of interleukin-6. Biol Chem. 2017;292:8136-48

15. Bergamaschi A, Madak-Erdogan Z, Kim YJ, Choi YL, Lu HL, Katzenellenbogen BS. The forkhead transcription factor FOXM1 promotes endocrine resistance and invasiveness in estrogen receptor-positive breast cancer by expansion of stem-like cancer cells. Breast Cancer Res. 2014;16:436.

16. Kim SH, Kaschula CH, Priedigkeit N, Lee AV, Singh SV. Forkhead box Q1 is a novel target of breast Cancer stem cell inhibition by Diallyl Trisulfide. J Biol Chem. 2016;291:13495-508.

17. Yang Z, Jiang S, Cheng YC, Li T, Hu W, Ma ZQ, Chen FL, Yang Y. FOXC1 in cancer development and therapy: deciphering its emerging and divergent roles. Ther Adv Med Oncol. 2017:9:797-816.

18. Chen SM, Jiao SC, Jia YC, Li Y. Effects of targeted silencing of FOXC1 gene on proliferation and in vitro migration of human non-small-cell lung carcinoma cells. Am J Transl Res. 2016:8:3309-18.
19. Lin YJ, Shyu WC, Chang CW, Wang CC, Wu CP, Lee HT, Chen LJ, Hsieh CH. Tumor hypoxia regulates Forkhead box C1 to promote lung Cancer progression. Theranostics. 2017;7:1177-91.

20. Wei LX, Zhou RS, Xu HF, Wang JY, Yuan MH. High expression of FOXC1 is associated with poor clinical outcome in non-small cell lung cancer patients. Tumor Biol. 2013;34:941-6.

21. Xia LM, Huang WJ, Tian DA, Zhu HW, Qi XS, Chen Z, Zhang YG, Hu H, Fan DM, Nie YZ, et al. Overexpression of Forkhead box C1 promotes tumor metastasis and indicates poor prognosis in hepatocellular carcinoma. Hepatology. 2013;57:610-24.

22. Huang W, Chen Z, Zhang L, Tian D, Wang D, Fan D, Wu K, Xia L. Interleukin8 induces expression of FOXC1 to promote transactivation of CXCR1 and CCL2 in hepatocellular carcinoma cell lines and formation of metastases in mice. Gastroenterology. 2015;149:1053-67.

23. Sizemore ST, Keri RA. The forkhead box transcription factor FOXC promotes breast cancer invasion by inducing matrix metalloprotease 7 (MMP7) expression. J Biol Chem. 2012;287:24631-40.

24. Wang J, Ray PS, Sim MS, Zhou XZ, Lu KP, Lee AV, Lin X, Bagaria SP, Giuliano $A E$, Cui X. FOXC1 regulates the functions of human basal-like breast cancer cells by activating NF-kappaB signaling. Oncogene. 2012;31:4798-802.

25. Han B, Zhou B, Qu Y, Gao B, Xu Y, Chung S, Tanaka H, Yang W, Giuliano AE, Cui X. FOXC1-induced non-canonical WNT5A-MMP7 signaling regulates invasiveness in triple-negative breast cancer. Oncogene. 2018;37: 1399-408.

26. Yu-Rice Y, Jin Y, Han B, Qu Y, Johnson J, Watanabe T, Cheng L, Deng N, Tanaka H, Gao B, et al. FOXC1 is involved in ERalpha silencing by counteracting GATA3 binding and is implicated in endocrine resistance. Oncogene. 2016:35:5400-11.

27. Lay K, Kume T, Fuchs E. FOXC1 maintains the hair follicle stem cell niche and governs stem cell quiescence to preserve long-term tissueregenerating potential. Proc Natl Acad Sci U S A. 2016;113:E1506-15.

28. Wang $L$, Siegenthaler JA, Dowell RD, Yi R. Foxc1 reinforces quiescence in self-renewing hair follicle stem cells. Science. 2016;351:613-7.

29. Takebe N, Miele L, Harris PJ, Jeong W, Bando H, Kahn M, Yang S, Ivy SP. Targeting notch, hedgehog, and Wnt pathways in cancer stem cells: clinical update. Nat Rev Clin Oncol. 2015;12:445-64.

30. Hayashi $H$, Kume T. Foxc transcription factors directly regulate D\|4 and Hey2 expression by interacting with the VEGF-notch signaling pathways in endothelial cells. PLoS One. 2008;3:e2401.

31. Han BC, Qu Y, Jin YL, Yu Y, Deng N, Wawrowsky $K$, Zhang X, Li N, Bose S, Wang $Q$, et al. FOXC1 activates smoothened-independent hedgehog signaling in basal-like breast Cancer. Cell Rep. 2015;13:1046-58.

32. Hollier BG, Tinnirello AA, Werden SJ, Evans KW, Taube JH, Sarkar TR, Sphyris $\mathrm{N}$, Shariati M, Kumar SV, Battula VL, et al. FOXC2 expression links epithelialmesenchymal transition and stem cell properties in breast cancer. Cancer Res. 2013;73:1981-92.

33. Paranjape AN, Soundararajan R, Werden SJ, Joseph R, Taube JH, Liu H, Rodriguez-Canales J, Sphyris N, Wistuba I, Miura N, et al. Inhibition of FOXC2 restores epithelial phenotype and drug sensitivity in prostate cancer cells with stem-cell properties. Oncogene. 2016;35:5963-76.

34. Koizumi F, Shimoyama T, Taguchi F, Saijo N, Nishio K. Establishment of a human non-small cell lung cancer cell line resistant to gefitinib. Int J Cancer. 2005;116:36-44.

35. Chandrashekar DS, Bashel B, Balasubramanya SAH, Creighton CJ, PonceRodriguez I, Chakravarthi BVSK, Varambally S. UALCAN: a portal for facilitating tumor subgroup gene expression and survival analyses. Neoplasia. 2017;19:649-58.

36. Ponten $\mathrm{F}$, Jirstrom $\mathrm{K}$, Uhlen $\mathrm{M}$. The human protein atlas - a tool for pathology. J Pathol. 2008;216:387-93.

37. MacDonagh L, Gray SG, Breen E, Cuffe S, Finn SP, O'Byrne KJ, Barr MP. Lung cancer stem cells: the root of resistance. Cancer Lett. 2016;372:147-56.

38. Fennell DA, Summers Y, Cadranel J, Benepal T, Christoph DC, Lal R, Das M, Maxwell F, Visseren-Grul C, Ferry D. Cisplatin in the modern era: the backbone of first-line chemotherapy for non-small cell lung cancer. Cancer Treat Rev. 2016;44:42-50

39. Matikas A, Georgoulias $\vee$, Kotsakis A. The role of docetaxel in the treatment of non-small cell lung cancer lung cancer: an update. Expert Rev Respir Med. 2016:10:1229-41.

40. Costanzo R, Piccirillo MC, Sandomenico C, Carillio G, Montanino A, Daniele G, Giordano P, Bryce J, De Feo G, Di Maio M, et al. Gefitinib in non small cell lung Cancer. J Biomed Biotechnol. 2011;2011:815269. 
41. Kim $Y M$, Kahn $M$. The role of the Wnt signaling pathway in cancer stem cells: prospects for drug development. Res Rep Biochem. 2014;4:1-12.

42. Pierrou S, Hellqvist M, Samuelsson L, Enerback S, Carlsson P. Cloning and characterization of seven human forkhead proteins: binding site specificity and DNA bending. EMBO J. 1994;13:5002-12.

43. Samatar AA, Wang LQ, Mirza A, Koseoglu S, Liu SX, Kumar CC. Transforming growth factor-beta 2 is a transcriptional target for Akt/protein kinase B via forkhead transcription factor. J Biol Chem. 2002;277:28118-26.

44. Eramo A, Lotti F, Sette G, Pilozzi E, Biffoni M, Di Virgilio A, Conticello C, Ruco $L$, Peschle C, De Maria R. Identification and expansion of the tumorigenic lung cancer stem cell population. Cell Death Differ. 2008;15:504-14.

45. Bertolini G, Roz L, Perego P, Tortoreto M, Fontanella E, Gatti L, Pratesi G, Fabbri A, Andriani F, Tinelli S, et al. Highly tumorigenic lung cancer CD133(+ ) cells display stem-like features and are spared by cisplatin treatment. P Natl Acad Sci USA. 2009:106:16281-6.

46. Chiou SH, Wang ML, Chou YT, Chen CJ, Hong CF, Hsieh WJ, Chang HT, Chen YS, Lin TW, Hsu HS, et al. Coexpression of Oct4 and Nanog enhances malignancy in lung adenocarcinoma by inducing Cancer stem cell-like properties and epithelial-mesenchymal Transdifferentiation. Cancer Res. 2010;70:10433-44.

47. Singh S, Trevino J, Bora-Singhal N, Coppola D, Haura E, Altiok S, Chellappan SP. EGFR/Src/Akt signaling modulates Sox2 expression and self-renewal of stem-like side-population cells in non-small cell lung cancer. Mol Cancer. 2012;11:73.

48. Ho MM, Ng AV, Lam S, Hung JY. Side population in human lung cancer cell lines and tumors is enriched with stem-like cancer cells. Cancer Res. 2007; 67:4827-33.

49. Sullivan JP, Minna JD, Shay JW. Evidence for self-renewing lung cancer stem cells and their implications in tumor initiation, progression, and targeted therapy. Cancer Metastasis Rev. 2010;29:61-72.

50. Rotow J, Bivona TG. Understanding and targeting resistance mechanisms in NSCLC. Nat Rev Cancer. 2017;17:637-58.

51. Kim ES. Chemotherapy resistance in lung Cancer. Adv Exp Med Biol. 2016; 893:189-209.

52. Camidge DR, Pao W, Sequist LV. Acquired resistance to TKIs in solid tumours: learning from lung cancer. Nat Rev Clin Oncol. 2014;11:473-81.

53. Yong X, Tang B, Xiao YF, Xie R, Qin Y, Luo G, Hu CJ, Dong H, Yang SM. Helicobacter pylori upregulates Nanog and Oct4 via Wnt/beta-catenin signaling pathway to promote cancer stem cell-like properties in human gastric cancer. Cancer Lett. 2016;374:292-303.

54. Chau WK, Ip CK, Mak ASC, Lai HC, Wong AST. c-Kit mediates chemoresistance and tumor-initiating capacity of ovarian cancer cells through activation of Wnt/beta-catenin-ATP-binding cassette G2 signaling. Oncogene. 2013;32:2767-81.

55. Van Raay TJ, Moore KB, lordanova I, Steele M, Jamrich M, Harris WA, Vetter ML. Frizzled 5 signaling governs the neural potential of progenitors in the developing Xenopus retina. Neuron. 2005;46:23-36.

56. Kovalovsky D, Yu Y, Dose M, Emmanouilidou A, Konstantinou T, Germar K Aghajani K, Guo ZY, Mandal M, Gounari F. beta-Catenin/Tcf determines the outcome of Thymic selection in response to alpha beta TCR signaling. J Immunol. 2009;183:3873-84.

57. Kim JH, Park SY, Jun Y, Kim JY, Nam JS. Roles of Wnt target genes in the journey of Cancer stem cells. Int J Mol Sci. 2017; https://doi.org/10.3390/ ijms18081604

\section{Ready to submit your research? Choose BMC and benefit from:}

- fast, convenient online submission

- thorough peer review by experienced researchers in your field

- rapid publication on acceptance

- support for research data, including large and complex data types

- gold Open Access which fosters wider collaboration and increased citations

- maximum visibility for your research: over $100 \mathrm{M}$ website views per year

At BMC, research is always in progress.

Learn more biomedcentral.com/submissions 